\title{
Hidradenitis Suppurativa or Hidradenitis Suppurativa-Like Lesions Located on Amputation Stumps? Description of 2 Cases
}

\author{
Nicolas Kluger ${ }^{a} \quad$ Philippe Guillem $^{b, c}$ Minttu Kivivuorid ${ }^{d}$ Kirsi Isoherranen ${ }^{a}$ \\ a Department of Dermatology, Allergology and Venereology, Helsinki University Central Hospital, Helsinki, Finland; \\ ${ }^{b}$ Service de chirurgie adulte, clinique du Val-d'Ouest, Ecully, France; ${ }^{C}$ ResoVerneuil, France; ${ }^{\mathrm{d}}$ Department of \\ Dermatology, North Karelia Central Hospital, Joensuu, Finland
}

\section{Established Facts}

- Hidradenitis suppurativa may locate specifically in areas of chronic friction and pressure as an equivalent of a Koebner phenomenon.

\section{Novel Insights}

- Two cases of difficult-to-treat hidradenitis suppurativa or hidradenitis suppurativa-like lesions located to lower limb amputation stumps are reported.

\section{Keywords}

Amputation · Friction · Hidradenitis suppurativa · Prosthesis · Stump

\begin{abstract}
Hidradenitis suppurativa (HS) is a chronic and recurrent inflammatory skin disorder affecting mainly the areas rich in apocrine sweat glands, such as the axillae, groins and buttocks. The role of mechanical pressure and friction due to clothing in the pathogenesis of HS lesions has been previously stressed. Here, we report 2 middle-aged men who presented with HS lesions/HS-like lesions on their amputation stump and review 2 additional cases from the literature. Management was challenging as 2 patients needed tumor necrosis ainhibitor while deroofing/surgery was the option
\end{abstract}

for the 2 others. These cases highlight that mechanical pressure and friction are environmental factors that can play a role in the pathogenesis of HS lesions.

(c) 2019 S. Karger AG, Basel

\section{Introduction}

Hidradenitis suppurativa (HS) is a chronic and recurrent inflammatory skin disorder affecting mainly the areas rich in apocrine sweat glands $[1,2]$. HS patients have been reported to have a reduced life time expectancy, highlighting the need for a holistic treatment approach in this patient group [3]. Patients present painful inflammatory nodules, abscesses, comedones, scarring and tunneling sinus tracts mainly in the axillary, inguinal and ano-

\section{KARGER}

(C) 2019 S. Karger AG, Basel

E-Mail karger@karger.com

www.karger.com/sad
Nicolas Kluger

Department of Dermatology, Helsinki University Central Hospital

Meilahdentie 2, PO Box 160

FI-00029 Helsinki (Finland)

E-Mail nicolas.kluger@hus.fi 


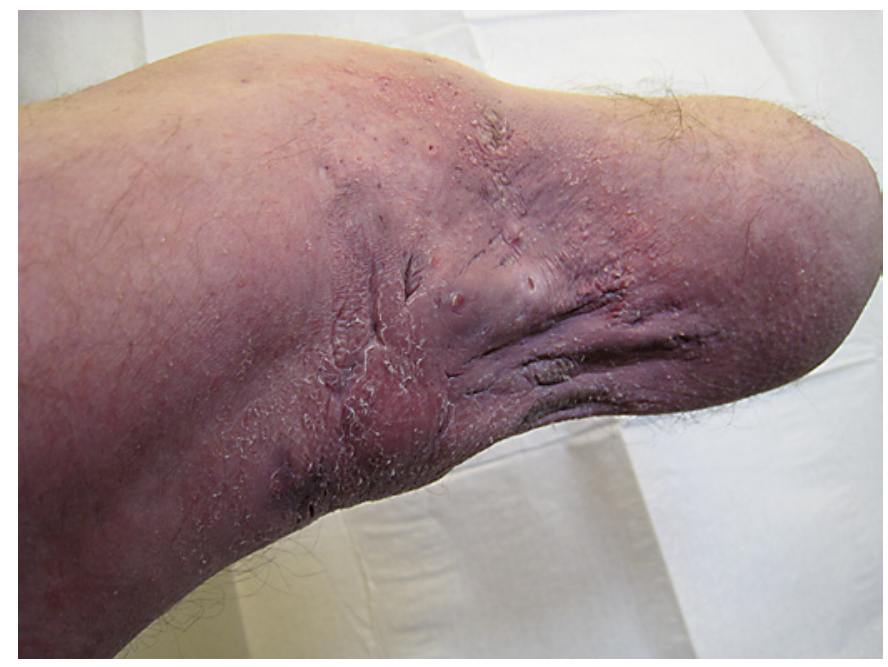

Fig. 1. HS-like lesions on the left amputation stump.

genital regions $[1,2]$. However, ectopic locations of HS in other body parts have been reported, and the role of chronic mechanical trauma and frictions has been questioned as a potential factor $[4,5]$. Friction avoidance is among the list of lifestyle modifications suggested to HS patients $[1,2]$. Amputation stumps are peculiar areas subjected to pressure, shear and friction. Acne mechanica [6] and epidermoid cysts [7] have been reported on amputation stumps as well as HS $[8,9]$. We report here 2 additional cases of HS localized on amputation stumps.

\section{Case Reports}

\section{Case 1}

The patient was a 55-year-old man with a history of metabolic syndrome (diabetes type 2 , hypertension, hypercholesterolemia), overweight (BMI 28.9) and Charcot-Marie-Tooth disease. He was a former smoker, still using snuff tobacco. He was first referred to us for the management of recurrent boils on his amputation stump in 2015. Amputation had been performed over a decade previously, at the end of 2001, because of his neurological condition. Within the next year recurrent boils appeared strictly on the stump. Upon examination, on the stump fistulas, abscesses and scars evocative of localized HS were found (Fig. 1). Physical examination revealed also folliculitis of the back, with open comedos and folliculitis of thighs. However, the patient did not have any other typical features of HS. Local antibiotics (clindamycin), oral rifampicin-clindamycin and acitretin were inefficient. The patient used multiple treatments combined such as local corticosteroids, acitretin and oral cephalexin. Tumor necrosis factor $\alpha$ inhibitor (adalimumab) was initiated in summer 2017 at the recommended regimen for HS (160 at week 0,80 at week 2 and $40 \mathrm{mg}$ weekly starting at week 4) [2]. Efficacy was notable after 3 months with relapses when treatment was withdrawn. At 1 year of follow-up, the patient still presents 1 or 2 flares monthly which is way better than before, and the patient is satisfied with such a result. Of note, he had developed an erysipelas under adalimumab.

Case 2

The patient was a 41-year-old man referred for the management of HS. He was an active smoker (10 pack-years) and obese (BMI 31.6). He had a first-degree relative with HS symptoms. HS began when he was 26 on the inner thighs. Other affected sites were the chest and abdominal folds. HS had previously been treated with local excisions and a 6-month course of doxycycline (with significant improvement during the course). A pilonidal sinus disease was excised in 2007 with local recurrence in 2017 treated with repeated excisions. Lower limb amputation was performed in 2013 after a traffic accident. Hurley II boils, abscesses and fistulas appeared in 2017 on the stump, preventing the patient from wearing a permanent prosthesis. A 6-month course of doxycycline again induced a significant improvement of HS, including stump lesions, followed by relapse under treatment (Fig. 2). Combination by ofloxacin and clindamycin as previously reported [10] was inefficient. Lack of social care reimbursement of adalimumab in France prevented us from initiating this treatment. Surgery on active lesions on the pubis and axillary fold is planned before stump surgery.

\section{Discussion/Conclusion}

We report about 2 new cases of HS features localized on amputation stumps. The stump is exposed to constant friction, pressures and shear force, increased humidity and prolonged and moist contact with the prosthesis, resulting in exposure to its constituent chemical compounds [11]. Skin problems on amputation stumps affect from 16 to $70 \%$ of the patients according to several series [12-14]. Mechanically induced lesions such as verrucous hyperplasia, follicular hyperkeratosis or epidermoid cysts are broadly observed in $1.5-4 \%$ of the amputees $[13,14]$. To our knowledge, no case of HS lesions has been specifically reported in those series.

Our first patient did not meet the criteria for HS as he did not have any personal or familial history of HS, nor lesions in any typical areas of HS (namely axillae, groins or buttocks), so that the diagnosis remains HS-like lesions. Some authors have put forward mechanical stress as a trigger for the outburst of new lesions of HS [4, 5, 15, 16]. For instance, Boer [4] reported 14 patients with HS who had abdominal lesions corresponding to the waistband. In his series, patients were all with a BMI $>30$ and most of all smokers [4]. Such a phenomenon was also observed in the bra strap area in a woman [5]. To the best of our knowledge, a total of 4 cases ( 3 men [mean age 45] and a 24-year-old woman) of HS lesions/HS-like lesions on a leg stump have been reported (Table 1) $[8,9]$. Clinical presentation was highly variable: age at amputation 

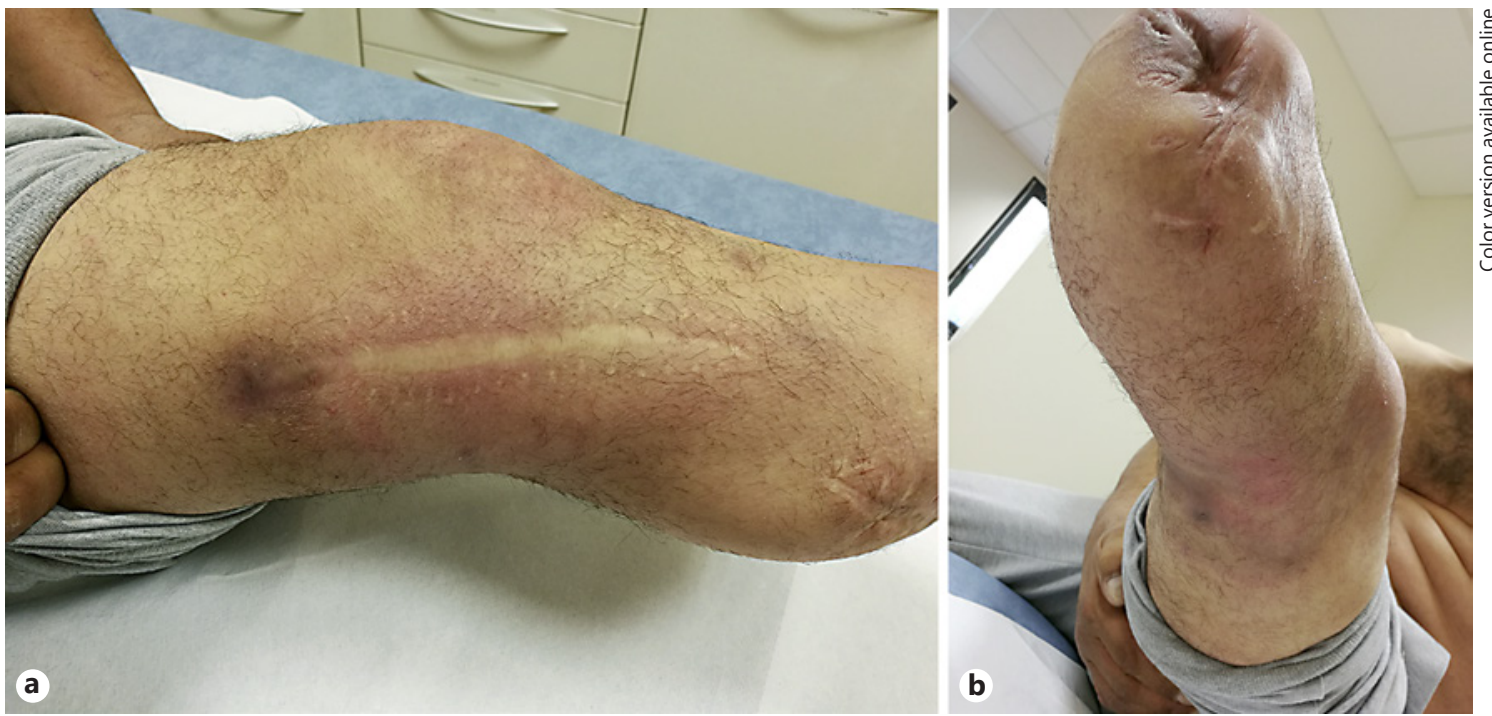

Fig. 2. a Boil on the upper part of a surgery scar on the inner side of the thigh. $\mathbf{b}$ Small boils on the posterior side of the thigh.

Table 1. Characteristics of all cases of HS on amputation stumps

\begin{tabular}{|c|c|c|c|c|c|c|c|c|}
\hline Reference & $\begin{array}{l}\text { Gender, } \\
\text { age, years }\end{array}$ & $\begin{array}{l}\text { Family } \\
\text { history } \\
\text { of HS }\end{array}$ & Habitus, comorbidities & $\begin{array}{l}\text { Other sites } \\
\text { affected by } \\
\text { HS }\end{array}$ & $\begin{array}{l}\text { Age at leg } \\
\text { amputation, } \\
\text { years }\end{array}$ & $\begin{array}{l}\text { Delay for HS } \\
\text { occurrence on } \\
\text { leg stump, years }\end{array}$ & $\begin{array}{l}\text { Administered } \\
\text { treatments }\end{array}$ & Efficiency \\
\hline $\begin{array}{l}\text { Present } \\
\text { case } 1\end{array}$ & $\begin{array}{l}\text { Male, } \\
51\end{array}$ & No & $\begin{array}{l}\text { Ex-smoker, snuff tobacco } \\
\text { BMI = 28.9 } \\
\text { Diabetes type II } \\
\text { Hypertension } \\
\text { Hypercholesterolemia } \\
\text { Charcot-Marie-Tooth disease }\end{array}$ & None & 38 & 1 & $\begin{array}{l}\text { Topical clindamycin } \\
\text { Rifampicin-clindamycin } \\
\text { Acitretin } \\
\text { Adalimumab }\end{array}$ & $\begin{array}{l}\text { None } \\
\text { None } \\
\text { None } \\
\text { Significant }\end{array}$ \\
\hline $\begin{array}{l}\text { Present } \\
\text { case } 2\end{array}$ & $\begin{array}{l}\text { Male, } \\
41\end{array}$ & $\begin{array}{l}\text { Yes } \\
\text { (first-de- } \\
\text { gree rela- } \\
\text { tive) }\end{array}$ & $\begin{array}{l}\text { Smoker } \\
\mathrm{BMI}=31.6 \\
\text { Pilonidal sinus disease }\end{array}$ & $\begin{array}{l}\text { Inner thighs } \\
\text { Abdominal } \\
\text { fold }\end{array}$ & 36 & 1 & $\begin{array}{l}\text { Doxycycline } \\
\text { Ofloxacin-clindamycin }\end{array}$ & $\begin{array}{l}\text { Initially signifi- } \\
\text { cant, relapse } \\
\text { None }\end{array}$ \\
\hline
\end{tabular}

ranged from 4 to 39 years and delay for onset from 1 to 8 years after amputation. Two patients had HS symptoms elsewhere, while 2 others had not. Treatment outcome varied with efficacy of biologics in 2 cases, initial efficacy of antibiotics in 1 and deroofing in 1 . In men, overweight/obesity, diabetes and smoking were found as cofactors.

At first glance, it is rather surprising that a stump can be the elective localization of HS lesions as it is not an area considered to be rich in apocrine sweat glands. Apocrine 
glands have a role in thermoregulation. They lower the surface tension of the sweat so that it forms a sheet rather than drops on the skin $[17,18]$. The stump is exposed to constant friction, pressures and shear force. Besides, the stump is fitted with a prosthesis which creates a warm environment and possibly increases sweating. Friction and skin confinement within a prosthesis would be both important in the physiopathogeny of the lesions in predisposed patients. Skin confinement may favor apocrine gland development and thereby apocrine gland disease. Overweight, obesity and tobacco are additional factors that could take part here in the phenomenon, even though they are not the sole triggers of the disease [19]. In the aforementioned studies of skin lesions in amputees [13, $14]$, neither smoking nor BMI were analyzed. Boer [4] reported a patient with abdominal waistband-induced HS lesions that improved with weight loss. In the case of amputation, the situation is more challenging as mechanical factors on the stump are unavoidable. In case of severe flare, it can be suggested to the patient to temporarily use a wheelchair or crutches, at the cost of an impact on the patient's quality of life. Even though the role of overweight/obesity and smoking on the stump lesions remains open, lifestyle modifications should be emphasized due to additional benefits for the patients' health.

In conclusion, HS or HS-like lesions may develop locally on leg stumps because of mechanical stress in patients with additional HS risk factors. Treatment is challenging as pressure and shear forces applied on the prosthesis are almost unavoidable and may expose to treatment failure. To date, no treatment appeared specifically beneficial. Biologics were necessary in half of the cases to provide relief.

\section{Statement of Ethics}

Subjects have given their consent to publish details and photos of the case.

\section{Disclosure Statement}

Dr. Nicolas Kluger has served as a consultant to AbbVie and has received research funding from $\mathrm{AbbVie}$ and speaker fees from AbbVie (2015-2016) and travel grants (2018) from AbbVie Finland. P. Guillem received honoraria from AbbVie and Novartis as a consultant and provided lectures for AbbVie, Brothier, Cicaplus, Coloplast and Novartis.

\section{Author Contributions}

M.K. and K.I.: acquisition, critical revision of the work. N.K. and P.G.: design of the work, acquisition, analysis and interpretation of the data, drafting of the work.

\section{References}

1 Alikhan A, Sayed C, Alavi A, et al. North American clinical management guidelines for hidradenitis suppurativa: a publication from the United States and Canadian Hidradenitis Suppurativa Foundations. I. Diagnosis, evaluation, and the use of complementary and procedural management. J Am Acad Dermatol. 2019 Jul;81(1):76-90.

2 Zouboulis CC, Desai N, Emtestam L, Hunger RE, Ioannides D, Juhász I, et al. European S1 guideline for the treatment of hidradenitis suppurativa/acne inversa. J Eur Acad Dermatol Venereol. 2015 Apr;29(4):619-44.

3 Tiri H, Jokelainen J, Timonen M, Tasanen K, Huilaja L. Substantially reduced life expectancy in patients with hidradenitis suppurativa: a Finnish nationwide registry study. Br J Dermatol. 2019 Jun;180(6):1543-4.

4 Boer J. Should Hidradenitis Suppurativa Be Included in Dermatoses Showing Koebnerization? Is It Friction or Fiction? Dermatology. 2017;233(1):47-52.

5 Boer J, Mihajlovic D. Boils at Frictional Locations in a Patient with Hidradenitis Suppurativa. Acta Dermatovenerol Croat. 2016 Dec; 24(4):303-4.
6 Strauss RM, Harrington CI. Stump acne: a new variant of acne mechanica and a cause of immobility. Br J Dermatol. 2001 Mar;144(3): 647-8.

7 Allende MF, Levy SW, Barnes GH. Epidermoid cysts in amputees. Acta Derm Venereol. 1963;43:56-67.

8 Henderson RL Jr. Case reports: treatment of atypical hidradenitis suppurativa with the tumor necrosis factor receptor-Fc fusion protein etanercept. J Drugs Dermatol. 2006 NovDec;5(10):1010-1.

9 de Winter K, van der Zee HH, Prens EP. Is mechanical stress an important pathogenic factor in hidradenitis suppurativa? Exp Dermatol. 2012 Mar;21(3):176-7.

10 Delaunay J, Villani AP, Guillem P, Tristan A, Boibieux A, Jullien D. Oral ofloxacin and clindamycin as an alternative to the classic rifampicin-clindamycin in hidradenitis suppurativa: retrospective analysis of 65 patients. Br J Dermatol. 2018 Jan;178(1):e15-6.

11 Meulenbelt HE, Geertzen JH, Dijkstra PU, Jonkman MF. Skin problems in lower limb amputees: an overview by case reports. J Eur Acad Dermatol Venereol. 2007 Feb;21(2):147-55.
12 Chan KM, Tan ES. Use of lower limb prosthesis among elderly amputees. Ann Acad Med Singapore. 1990 Nov;19(6):811-6.

13 Lyon CC, Kulkarni J, Zimerson E, Van Ross E, Beck MH. Skin disorders in amputees. J Am Acad Dermatol. 2000 Mar;42(3):501-7.

14 Colgecen E, Korkmaz M, Ozyurt K, Mermerkaya U, Kader C. A clinical evaluation of skin disorders of lower limb amputation sites. Int J Dermatol. 2016 Apr;55(4):468-72.

15 Boer J, Nazary M, Riis PT. The Role of Mechanical Stress in Hidradenitis Suppurativa. Dermatol Clin. 2016 Jan;34(1):37-43.

16 De Vita V, Fabbrocini G. Mechanical Stress as a Cause of Hidradenitis Suppurativa: A Lesson from a Patient with a Monster Hernia. Acta Dermatovenerol Croat. 2018 Oct;26(3):260-1.

17 Porter AM. Why do we have apocrine and sebaceous glands? J R Soc Med. 2001 May;94(5):236-7.

18 Lupi O. Ancient adaptations of human skin: why do we retain sebaceous and apocrine glands? Int J Dermatol. 2008 Jul;47(7):651-4.

19 Wollina U, Langner D, Heinig B, Nowak A. Comorbidities, treatment, and outcome in severe anogenital inverse acne (hidradenitis suppurativa): a 15 -year single center report. Int J Dermatol. 2017 Jan;56(1):109-15. 